\title{
STRATEGI PENERJEMAHAN FRASA NOMINAL PADA SUBTITLE FILM MONKEY KING 2
}

\section{STRATEGY OF NOUN PHRASES UTILIZED IN MONKEY KING 2 MOVIE'S SUBTITLES}

\author{
Nurhayati ${ }^{1 a}$ \\ ${ }^{1}$ Program Studi Diploma Bahasa Mandarin, Fakultas Ilmu Budaya, Universitas Jenderal Soedirman \\ Komp. Unsoed Karangwangkal Purwokerto Jl. Dr. Soeparno \\ a Korespondensi: Nurhayati, Email: nuoni.zf@gmail.com
}

(Diterima: 23-08-2017; Ditelaah: 24-08-2017; Disetujui: 04-10-2017)

\begin{abstract}
The objective of this article is to identify the noun phrases, and to analize the strategies applied by the the translator to translate this movie's subtitles. The research uses the descriptive qualitative method. The Monkey King 2 movie's subtitles serves as the source teks for this research. The results show that the translator uses some strategies in translating subtitle, they are literal translation, free translation, paraphrase, replacements, antonimic translation, compensation, additions, omission, and descriptive translation. In addition, this research also finds some noun phrases in this movie's subtitles have unequivalent meaning.
\end{abstract}

Keywords: noun phrase, strategy, subtitle

\begin{abstract}
ABSTRAK
Tujuan penelitian ini adalah mengidentifikasi frasa nominal dan menganalisis strategi yang digunakan oleh penerjemah dalam menerjemahkan subtitle film ini. Penelitian ini menggunakan metode deskriptif kualitatif. Objek penelitian ini adalah subtitle film Monkey King 2 sebagai teks sumber. Hasil analisis menunjukkan bahwa penerjemah menggunakan berbagai strategi dalam menerjemahkan yaitu terjemahan harfiah, terjemahan bebas, parafrasa, penggantian, terjemahan antonim, kompensasi, penambahan, penghilangan, dan terjemahan deskriptif. Selain itu, terdapat beberapa penyimpangan pada frasa nominal dalam penerjemahan subtitle film Monkey King 2.
\end{abstract}

Kata kunci: frasa nominal, strategi, subtitle

Nurhayati. 2017. Strategi penerjemahan frasa nominal pada subtitle film Monkey King 2. Jurnal Sosial Humaniora 8(2): 104 - 111.

\section{PENDAHULUAN}

Penikmat film khususnya masyarakat Indonesia sangat menyukai film karya anak bangsa dan film asing seperti film Hollywood maupun film Tiongkok, genre film yang ditonton juga beragam, mulai dari film anakanak, dewasa, komedi, drama, horor dan film laga. Namun terdapat kendala bagi penikmat film asing karena adanya perbedaan bahasa.
Bahasa yang digunakan khususnya di dalam film Tiongkok adalah bahasa Mandarin, terdapat beberapa berbedaan struktur kalimat, idiom, dan istilah budaya yang terdapat di setiap film Tiongkok. Salah satunya adalah film Monkey King 2, yang merupakan film fantasi dengan menggunakan bahasa Mandarin sebagai bahasa pengantar (BSu). Agar dapat memahami makna pesan film tersebut dibutuhkan terjemahan subtitle yang singkat, 
padat dan tepat sasaran. Sehingga dapat membuat orang yang menonton film menjadi larut dalam alur cerita.

Menerjemahkan teks dari satu bahasa yang disebut dengan bahasa sumber (BSu) ke bahasa lain yang disebut dengan bahasa sasaran (BSa) tanpa mengubah isi teks asli disebut dengan proses terjemahan. Pesan yang terdapat di dalam $\mathrm{BSu}$ harus dipertahankan, dan tidak boleh hilang di dalam BSa. Adapun penerjemahan terbagi atas dua yaitu penerjemahan tulis seperti menerjemahkan dokumen, buku atau hal-hal yang berhubungan dengan tulisan/teks, sedangkan penerjemahan lisan (interpreter), termasuk juga penerjemahan film walaupun ada perbedaan karena penerjemahan film televisi bertumpu pada audio dan visual. Penerjemahan film televisi terbagi atas dua, yaitu dubbing/sulih suara dan subtitling. Subtitle merupakan teks terjemahan yang muncul di bagian bawah layar film. Kesulitan dalam penerjemahan film ini adalah keterbatasan waktu dalam menampilkan teks tiap kalimat dan jumlah karakter huruf untuk menampilkan subtitle di dalam layar.

Agar dapat menerjemahkan kalimat dengan baik, perlu diperhatikan kesesuaian posisi setiap kategori pada tataran frasa, salah satunya adalah kategori nominal. Terdapat beberapa perbedaan antara bahasa Indonesia dan bahasa Mandarin khususnya dalam frasa nominal, antara lain: 1) dari segi bentuk, nomina bahasa Indonesia terdiri atas nomina yang berbentuk kata dasar, dan nomina turunan yang dibentuk melalui afiksasi, perulangan, dan pemajemukan. Sedangkan bahasa Mandarin tidak dibentuk melalui afiksasi, perulangan, dan pemajemukan. 2) fungsi nomina, frasa nominal bahasa Indonesia mengalami perluasan ke kiri menggunakan struktur MD (menerangkan diterangkan), jika diikuti numeralia dan kata bantu numeralia, dan juga mengalami perluasan ke kanan menggunakan struktur DM (diterangkan menerangkan). Sebaliknya frasa nominal bahasa Mandarin, umumnya menggunakan struktur MD yaitu nomina yang diikuti oleh nomina lainnya, verba, adjektiva, pronomina, numeralia, frasa, keterangan tempat dan keterangan penunjuk arah. Namun pada frasa koordinatif menggunakan struktur DM. Frasa nominal bahasa Mandarin terdiri dari dua kata penuh dan frasa tetap. 3) Faktor penting dalam konstruksi sintaksis adalah urutan kata. Baik urutan kata frasa nominal dalam bahasa Indonesia maupun bahasa Mandarin tidak dapat ditukar karena maknanya akan berbeda. Begitu pula dengan nada kata atau ton, jika melafalkannya tidak tepat maka akan berbeda maknanya. Sebaliknya intonasi dalam pengucapan bahasa Indonesia tidak merubah makna, hanya untuk mengetahui suara yang meninggi, mendatar, atau menurun pada akhir ujaran. Dari penjelasan di atas dapat dilihat bahwa frasa nominal memegang peranan yang penting dalam konstruksi sintaksis, jika penerjemahannya tidak akurat maka maknanya menjadi berbeda.

Tujuan dari penelitian ini adalah mengidentifikasi frasa nominal dan menganalisis strategi yang digunakan oleh penerjemah dalam menerjemahkan subtitle film Monkey King 2, dan penulis hanya membatasi pada strategi penerjemahan yang dikemukakan oleh Moentaha.

\section{MATERI DAN METODE}

\section{Materi}

Seorang atau sekelompok penerjemah khususnya penerjemah subtitle dituntut untuk dapat menerjemahkan sebuah teks dengan baik, namun hal itu tidaklah mudah, penerjemah akan menemukan banyak kesulitan, kesulitan-kesulitan itu antara lain berhubungan dengan makna, baik makna leksikal, makna gramatikal, makna kontekstual, makna tekstual, maupun makna sosio-kultural. Selain itu, adanya batasan dalam subtitle yaitu perubahan dari bahasa lisan ke bahasa tulis, faktor-faktor yang mengatur penyampaian subtitle, pengurangan teks sumber akibat jumlah waktu penayangan subtitle yang terbatas, dan persyaratan untuk mencocokan citra visual. Namun kesulitan-kesulitan tersebut 
dapat diatasi jika seorang atau kelompok penerjemah berhati-hati, sabar dan teliti dalam menerjemahkan suatu teks agar tidak terjadi kesalahan atau penyimpangan. Menurut Lina Ho (2015) prinsip subtitling harus menggunakan bahasa yang singkat, padat, dan tepat sasaran, dan membantu pemirsa memahami isi film, bukan membuat pemirsa sibuk membaca. Agar penerjemahan subtitle memenuhi persyaratan, maka perlu menggunakan strategi penerjemahan, salah satunya strategi penerjemahan Moentaha (2008). Berikut adalah penjelasan singkatnya.

1. Terjemahan harfiah (literal translation) yaitu penerjemahan yang hasil realisasinya berada di bawah standar, yangmana hasil terjemahan cukup menyampaikan informasi teks BSu ke dalam teks BSa dengan mematuhi normanorma BSa.

2. Subtitusi (substitution) yaitu penerjemahan yang realisasinya dilakukan dari bentuk BSu ke bentuk BSa dengan melalui makna.

3. Terjemahan bebas (free translation) yaitu terjemahan yang dilakukan di tingkat kata maupun kalimat, dan biasanya terjemahan ini tidak terjadi penyimpangan makna, maupun pelanggaran norma-norma

4. Parafrasa (paraphrase) yaitu penerjemahan yang mempertahankan informasi yang ada dalam teks BSu dalam bentuk gambaran situasi dan bukan makna teks BSu

5. Penggantian (replacements) yaitu strategi penerjemahan yang mengalami penggantian satuan-satuan gramatikal (kelas kata, bagian kalimat), satuansatuan leksikal (kata-kata tertentu), dan konstruksi-konstruksi kalimat.

a. Penggantian kelas kata yaitu penggantian kategori nomina menjadi verba atau penggantian kategori lainnya.

b. Penggantian bagian-bagian kalimat yaitu kata-kata dalam teks bahasa sumber tidak sama fungsi sintaksisnya dengan terjemahan teks bahasa sasaran.

c. Penggantian leksikal dibagi dua yaitu (1) konkretisasi (dari luas ke sempit), makna yang luas dalam bahasa sumber diterjemahkan menjadi makna yang lebih sempit ke dalam bahasa sasaran. (2) generalisasi (dari sempit ke luas), makna yang sempit dalam bahasa sumber diterjemahkan menjadi makna yang lebih luas ke dalam bahasa sasaran.

d. Terjemahan antonim (antonimic translation) yaitu penggantian kata dalam satu bahasa dengan antonimnya dalam bahasa lain dengan perubahan kalimat berita menjadi kalimat sangkal.

e. Kompensasi (compensation) yaitu strategi penerjemahan ini dilakukan karena adanya ketidakmungkinan penyampaian informasi yang terkandung dalam satuan BSu pada satuan $\mathrm{BSa}$.

6. Penambahan (additions) yaitu penambahan leksikal pada teks BSa jika maksud isi teks BSu diungkapkan dengan sarana lain termasuk sarana gramatikal

7. Penghilangan (omission/dropping) yaitu membuang kata yang berlimpah karena tanpa kata yang berlimpah itu, isi informasi dalam teks BSu dapat secara utuh disampaikan ke dalam BSa.

8. Kompresi (compression) yaitu buah pikiran yang sama bisa diungkapkan dalam berbagai cara menjadi lebih padat, lebih singkat dan ringkas dari BSu ke dalam BSa.

9. Derivasi sintaksis (syntactic derivation) yaitu proses pembentukan berbagai konstruksi sintaksis dengan cara mengubah posisi bagian kalimat yang satu atau yang lain.

10. Terjemahan deskriptif (descriptive translation) Amplifikasi (amplification) yaitu menyampaikan makna teks BSu ke dalam teks BSa dengan menggunakan kombinasi kata-kata bebas dengan menjelaskan satuan-satuan leksikal yang 
mencerminkan realitas spesifik negara yang satu atau yang lain

11. Eksplikasi / Implikasi (explication / implication) yaitu merealisasi pengungkapan eksplisit dalam teks BSa, karena ada implikasi dalam informasi teks BSu sehingga pengungkapannya tidak jelas.

\section{Metode}

Metode penelitian ini merupakan metode analisis isi yang bersifat deskriptif yang merupakan bagian dari penelitian kualitatif. Dalam penelitian ini penulis akan memaparkan strategi yang digunakan oleh penerjemah dalam menerjemahkan frasa nominal pada subtitle film Monkey King 2. Bahasa sumber yang digunakan dalam film ini adalah bahasa Mandarin, dan subtitle film Monkey King 2 dalam bahasa Indonesia sebagai bahasa sasaran.

\section{HASIL DAN PEMBAHASAN}

\section{Strategi Penerjemahan Film Monkey King 2}

\section{Terjemahan \\ harfiah translation)}

Cliteral

Contoh frasa nominal berstruktur nomina + nomina (名词加名词) :

\section{$\mathrm{BSu}$ : 佛的正道}

\section{fó de zhèngdào}

BSa : ajaran Buddha (01:31:41)

Frasa 佛的正道 (fó de zhèngdào) dialihbahasakan ke dalam bahasa Indonesia menjadi ajaran Buddha. Menurut kamus Tionghoa-Indonesia, kata 佛 (fó) artinya Buddha, dan kata 正道 (zhèngdào) artinya ajaran. Jika diterjemahkan menjadi ajaran Buddha. Pada frasa nominal bahasa Mandarin ini, kata ajaran merupakan inti dan kata Buddha merupakan pewatas, di antara inti dan pewatas disisipkan kata 的 (de) yang artinya kepemilikan atau yang. Dari penerjemahan ini menunjukkan bahwa penerjemah menggunakan strategi penerjemahan harfiah karena hasil terjemahannya sesuai dengan norma-norma BSa. Walaupun terdapat perbedaan dalam struktur kalimat, namun maknanya tetap sama.

\section{Terjemahan bebas (free translation)}

Contoh frasa nominal berstruktur nomina + nomina (名词加名词) :

$\mathrm{BSu}$ : 世间良药 shijiān liángyào

BSa : Waktu yang berlalu bukan semestinya suatu penyembuhan yang baik. (00:41:33)

Frasa 世间良药 (shìiān liángyào) dialihbahasakan ke dalam bahasa Indonesia menjadi waktu yang berlalu bukan semestinya suatu penyembuhan yang baik. Menunjukkan bahwa penerjemah menggunakan strategi penerjemahan bebas karena menggunakan kata-kata bebas dalam menyampaikan maknanya. Menurut aplikasi kamus elektronik Mandarin Pleco, kata 世间 (shìjiān) artinya di dunia atau di masyarakat dan kata 良药 (liángyào) artinya obat yang baik atau penyembuhan yang baik. Jika diterjemahkan di tingkat frasa menjadi penyembuhan yang baik di masyarakat, namun penerjemahannya dilakukan di tingkat kalimat secara keseluruhan. Dalam kalimat ini, frasa nominal bahasa Mandarin menggunakan struktur MD (menerangkanditerangkan).

\section{Parafrasa (paraphrase)}

Contoh frasa nominal berstruktur nomina + nomina (名词加名词) :

\section{$\mathrm{BSu}$ : 白骨夫人 báigǔ fūrén}

Bsa: Siluman Tengkorak Putih 00:14:43)

Frasa 白骨夫 人 (báigǔ fūrén) dialihbahasakan ke dalam bahasa Indonesia menjadi Siluman Tengkorak Putih. Menurut aplikasi kamus elektronik Mandarin Pleco, kata 白骨 (báigǔ) artinya tengkorak putih, 
dan kata 夫人 (fürén) artinya nyonya, istri, atau wanita yang berkedudukan tinggi, sehingga dapat diartikan sebagai ratu. Jika diterjemahkan secara harfiah menjadi Ratu Tengkorak Putih. Dari penerjemahan ini menunjukkan bahwa penerjemah menggunakan strategi penerjemahan parafrasa karena berdasarkan gambaran situasi cerita dalam film Monkey King 2, Ratu Tengkorak Putih adalah seorang siluman. Sehingga, penerjemah mengganti kata ratu menjadi kata siluman. Pada frasa nominal bahasa Mandarin ini, kata ratu merupakan inti dan kata tengkorak putih merupakan pewatas.

\section{Penggantian (Replacements)}

\section{Penggantian Kelas Kata}

Contoh frasa nominal berstruktur nomina + numeralia (名词加数量词) :

$$
\begin{aligned}
\mathrm{BSu}: & \text { 一丝希望 } \\
& y \bar{i} s \bar{x} \text { xīwàng }
\end{aligned}
$$

BSa : sinar harapan $\quad 01: 44: 18)$

$$
\text { Frasa - 丝希望 (yīsī xīwàng) }
$$

dialihbahasakan ke dalam bahasa Indonesia menjadi sinar harapan. Menurut kamus praktis Tionghoa-Indonesia, kata - (yī) artinya satu dan kata 希望 (Xīwàng) artinya harapan. Di antara kata - (yī) dan kata 希望 (xîwàng) disisipkan kata 丝 (sī) yang merupakan kata bantu bilangan. Jika diterjemahkan secara harfiah menjadi sebuah harapan. Dari penerjemahan ini menunjukkan bahwa penerjemah menggunakan strategi penggantian kelas kata karena terdapat perubahan kelas kata dari nomina+numeralia menjadi nomina+adjektiva. Kalimat yang diikuti oleh numeralia dan kata bantu numeralia, dalam bahasa Indonesia mengalami perlauasan ke kiri sama dengan bahasa Mandarin.

\section{Penggantian bagian-bagian kalimat}

Contoh frasa nominal berstruktur nomina + pronomina (名词加代词) :

$$
\text { zhèlǐ yāo qì }
$$

BSa : berbau siluman disini (00:32:42)

Frasa 这里奸气 (zhèlǐ yāo qì) dialihbahasakan ke dalam bahasa Indonesia menjadi berbau siluman disini. Menurut kamus praktis Tionghoa-Indonesia, kata 这 里 (zhèlǐ) artinya disini dan kata 妖气 (yāo qì) artinya bau siluman. Jika diterjemahkan menjadi bau siluman disini. Dari penerjemahan ini menunjukkan bahwa penerjemah menggunakan strategi penggantian bagian-bagian kalimat karena terdapat perubahan struktur kalimat sekaligus penggantian kelas kata. Kata disini dalam bahasa Mandarin diletakkan di depan kalimat. Sebaliknya dalam bahasa Indonesia diletakkan di belakang kalimat. selain itu, pada kata bau terdapat penggantian kelas kata dari nomina menjadi verba.

\section{Penggantian Leksikal}

\section{Konkretisasi}

Contoh frasa nominal berstruktur nomina + keterangan tempat (名词加处所词) :

\section{$\mathrm{BSu}$ : 城内 \\ chéngnèi}

BSa : kota (00:53:19)

Frasa 城内 (chéngnèi) dialihbahasakan ke dalam bahasa Indonesia menjadi kota. Menurut kamus praktis Tionghoa-Indonesia kata 城(chéng) artinya kota, dan kata 内 (nèi) artinya dalam. Jika diterjemahkan menjadi dalam kota. Dari penerjemahan ini menunjukkan bahwa penerjemah menggunakan strategi penggantian leksikal konkretisasi yangmana makna yang lebih luas diganti dengan makna yang lebih sempit. Dalam bahasa Indonesia, kata dalam merupakan bagian dari frasa nominal yang tidak wajib muncul. Sehingga frasa dalam kota dalam bahasa Indonesia diterjemahkan menjadi kata kota. Dalam kalimat ini, frasa nominal bahasa Mandarin menggunakan struktur MD (menerangkan-diterangkan).

\section{Generalisasi}


Contoh frasa nominal berstruktur nomina + pronomina (名词加代词) :

\section{$\mathrm{BSu}$ : 你的前世}

nǐ de qiánshì

BSa : kehidupanmu yang sebelumnya (01:25:32)

Frasa 你 的 前世 (nǐ de qiánshì) dialihbahasakan ke dalam bahasa Indonesia menjadi kehidupanmu yang sebelumnya. Menurut kamus praktis Tionghoa-Indonesia, kata 你 (nì) artinya kamu, dan kata 前世 (qiánshi) artinya kehidupan sebelumnya. Jika diterjemahkan menjadi kehidupanmu yang sebelumnya. Dari penerjemahan ini menunjukkan bahwa penerjemah menggunakan strategi penggantian leksikal generalisasi, yangmana makna yang sempit diganti dengan makna yang lebih luas. Kata 前世 (qiánshi) diterjemahkan menjadi frasa kehidupan sebelumnya. Dalam bahasa Mandarin, kata 前世 (qiánshi) sebagai inti dan kata 你 (nĭ) sebagai pewatas, dan di antara kedua kata tersebut disisipkan kata 的(de) yang artinya kepemilikan atau yang.

\section{Terjemahan \\ antonim \\ (antonimic translation)}

Contoh frasa nominal berstruktur nomina + frasa (名词加短语) :

\section{$\mathrm{BSu}$ : 到不了的西天

$$
\text { dào bùliăo de xītiān }
$$

BSa : mencapai arah Barat (01:28:37)

Klausa 到不了的西天 (dào bùliăo de xītiān) dialihbahasakan ke dalam bahasa Indonesia menjadi bisa mencapai arah Barat. Menurut kamus praktis Tionghoa-Indonesia, frasa 到 不了 (dào bùliăo) artinya tidak dapat mencapai, merupakan pelengkap kemungkinan (可能补语 kěnéng bŭyŭ) dan kata 西天 (xītiān) artinya Barat. Jika diterjemahkan menjadi ke Barat yang tidak dapat dicapai. Dalam konteks kalimatnya, di depan frasa 到不了 (dào bùliăo) terdapat kata 没有 (méiyǒu) yang artinya tidak ada, sehingga kalimat ini diterjemahkan menjadi tidak ada yang tidak dapat mencapai Barat.
Dari penerjemahan ini menunjukkan bahwa penerjemah menggunakan strategi terjemahan antonim, yangmana kalimat sangkal dalam bahasa sumber diganti menjadi kalimat berita dalam bahasa sasaran.

\section{Kompensasi (compensation)}

Contoh frasa nominal berstruktur nomina + adjektiva (名词加形容词) :

$\mathrm{BSu}$ : 小和尚

xiăo héshàng

BSa : Botak! (00:08:38)

Frasa 小 和 尚 (xiăo héshàng) dialihbahasakan ke dalam bahasa Indonesia menjadi botak. Menurut kamus praktis Tionghoa-Indonesia, kata 小 (xiăo) artinya kecil dan kata 和尚 (héshàng) artinya biksu. Jika diterjemahkan menjadi biksu muda. Dalam konteks kalimatnya, Sungokong sedang marah-marah kepada biksu Tang, sehingga penerjemah menggunakan strategi penerjemahan kompensasi. Karena adanya ketidakmungkinan menyampaikan informasi yang terkandung dalam suatu kalimat.

\section{Penambahan (additions)}

Contoh frasa nominal berstruktur nomina + pronomina (名词加代词) :

\section{$\mathrm{BSu}$ : 这个世界的真相}

\section{zhège shìjiè de zhēnxiàng}

Bsa: Kebenaran tentang dunia ini. (00:22:04)

Frasa 这个世界的真相 (zhège shìjiè de zhēnxiàng) dialihbahasakan ke dalam bahasa Indonesia menjadi kebenaran tentang dunia ini. Menurut kamus praktis TionghoaIndonesia, kata 这个(zhè ge) artinya ini, kata 世界 (shìiè) artinya dunia, kata 真相 (zhēnxiàng) artinya kebenaran. Jika diterjemahkan secara harfiah menjadi kebenaran dunia ini. Dari penerjemahan ini menunjukkan bahwa penerjemah menggunakan strategi penambahan (additions), karena adanya penambahan kata tentang pada frasa kebenaran dunia ini. Pada frasa nominal bahasa Mandarin ini, kata 
kebenaran merupakan inti dan kata dunia ini merupakan pewatas, di antara inti dan pewatas disisipkan kata 的 (de) yang artinya kepemilikan atau yang.

\section{Penghilangan (omission/dropping)}

Contoh frasa nominal berstruktur nomina + pronomina (名词加代词) :

\section{$\mathrm{BSu}$ ：俺老孙的火眼金睛}

Ăn lăo sūn de huǒyănjīnjīng

BSa : mata apiku (00:22:15)

Frasa 俺老孙的火眼金睛 ( $\breve{n}$ lăo sūn de huǒyănjinjīng) dialihbahasakan ke dalam bahasa Indonesia menjadi mata apiku. Menurut kamus praktis Tionghoa-Indonesia, kata 俺老孙 ( $\breve{n}$ lăo sūn) artinya aku Sungokong, dan kata 火 眼 金 睛 ( huǒyănjīnjīng) artinya mata api merupakan frasa tetap. Jika diterjemahkan menjadi mata apiku Sungokong. Dari penerjemahan ini menunjukkan bahwa penerjemah menggunakan strategi penghilangan (omission) dengan menghilangkan atau membuang kata Sunkogong. Dalam konteks kalimatnya, yang sedang melakukan dialog adalah Sungokong sehingga kata Sungokong tidak diterjemahkan, karena tanpa kata Sungokong makna frasa tersebut tetap utuh.

\section{Terjemahan deskriptif (descriptive translation) amplifikasi (amplification)}

Contoh frasa nominal berstruktur nomina + adjektiva (名词加形容词):

$$
\mathrm{BSu} \text { : 大闹 }
$$

\section{dà nào}

Bsa : malapetaka si raja kera (00:01:11)

Frasa 大闹 (dà nào) dialihbahasakan ke dalam bahasa Indonesia menjadi malapetaka si raja kera. Menunjukkan bahwa penerjemah menggunakan strategi terjemahan deskriptif yaitu menyampaikan makna frasa menggunakan kata-kata bebas. Menurut kamus praktis Tionghoa-Indonesia, kata 大闹 (dà nào) memiliki arti keributan besar. Namun menurut aplikasi kamus elektronik Mandarin Pleco, kata 大闹 (dà nào) memiliki arti penyebab malapetaka yang terjadi di istana langit yang dilakukan oleh si raja kera yaitu Sunkogong. Sehingga penerjemahannya mengalami perluasan dari bahasa sumber ke bahasa sasaran.

\section{Penyimpangan dalam Penerjemahan}

Contoh frasa nominal berstruktur nomina + keterangan penunjuk arah (名词加方位词)

$\mathrm{BSu}$ : 前面那个山

qiánmiàn nàgè shān

BSa : oh benarkah? (00:18:36)

Frasa 前面那个山 (qiánmiàn nàgè shān) dialihbahasakan ke dalam bahasa Indonesia menjadi kudengar dari pak tua. Menurut kamus praktis Tionghoa-Indonesia kata 前面 (qiánmiàn) artinya di depan, dan kata 山 (shān) artinya gunung, dan diantara kedua kata tersebut disisipkan kata 那个 (nà gè) yang artinya itu. Jika diterjemahkan menjadi gunung yang di depan itu. Dari penerjemahan ini menunjukkan bahwa penerjemah melakukan penyimpangan atau kesalahan karena frasa gunung yang di depan itu diterjemahkan menjadi frasa kudengar dari pak tua.

Contoh frasa nominal berstruktur nomina + pronomina (名词加代词) :

$\mathrm{BSu}$ : 这个老家伙

zhège lăo jiāhuo

BSa : gosip lama (00:57:26)

Frasa 这个老家伙 (zhège lăo jiāhuo) dialihbahasakan ke dalam bahasa Indonesia menjadi gosip lama. Menurut kamus praktis Tionghoa-Indonesia kata 这 (zhè) artinya ini, dan kata 老家伙 (lăo jiāhuo) artinya teman lama, diantara kedua kata tersebut disisipkan kata 个 (ge) yang merupakan kata bantu bilangan. Jika diterjemahkan menjadi teman lama ini. Dari penerjemahan ini menunjukkan bahwa penerjemah melakukan penyimpangan atau kesalahan karena menerjemahkan kata teman menjadi kata gosip, dan tidak menerjemahkan kata ini. 


\section{Contoh frasa nominal berstruktur nomina + numeralia (名词加数量词)}

$$
\begin{gathered}
\mathrm{BSu}: \text { 四十九道 } \\
\text { sìshíjiǔ dào }
\end{gathered}
$$

BSa : 29 dosis (01:02:26)

Frasa 四十九道 (sìshíjiǔ dào) dialihbahasakan ke dalam bahasa Indonesia menjadi 29 dosis. Menurut kamus praktis Tionghoa-Indonesia kata 四十九 (sìshíjiǔ) artinya 49, dan kata 道 (dào) artinya dosis. Jika diterjemahkan menjadi 49 dosis. Dari penerjemahan ini menunjukkan bahwa penerjemah melakukan penyimpangan atau kesalahan karena menerjemahkan angka 49 menjadi angka 29.

\section{KESIMPULAN DAN IMPLIKASI}

Dari hasil temuan dan pembahasan yang telah dipaparkan, dapat diambil kesimpulan sebagai berikut:

1. Penerjemah mampu mentransfer pesan dari bahasa Mandarin sebagai bahasa sumber ke dalam bahasa Indonesia sebagai bahasa sasaran dengan bahasa yang komunikatif dan jelas. Berdasarkan penelitian ini, Terdapat delapan bentuk frasa nominal bahasa Mandarin dalam film Monkey King 2 dengan struktur nomina+nomina (名词加名词 míngcí jiā míngcí), nomina+pronomina (名词加代 词 míngcíjiā dàicí), nomina+adjektiva (名 词加形容词 míngcí jiā xíngróngcî), nomina+verba (名词加 动词 míngcí jiā dòngcí ), nomina+frasa (名词加短语 míngcí jiā dŭanyŭ), nomina+numeralia (名词加数量词 míngcí jiā shùliàngcí), nomina+keterangan tempat (名词加处 所 词 míngcí jiā chùsuŏcî), dan nomina+keterangan penunjuk arah (名词 加方位词 míngcí jiā fāngwèicí).
2. Strategi-strategi penerjemahan yang digunakan untuk menerjemahkan film Monkey King 2 adalah terjemahan harfiah, terjemahan bebas, parafrasa, penggantian, terjemahan antonim, kompensasi, penambahan, penghilangan, dan terjemahan deskriptif. Strategi yang paling banyak dilakukan adalah strategi pengurangan (omission).

3. Dalam penerjemahan film Monkey King 2 ini, terdapat beberapa penyimpangan dalam penerjemahan. Sebagian besar penyimpangan yang terjadi adalah penyimpangan gramatikal dan leksikal, karena adanya perbedaan struktur teks sumber dan teks sasaran. Selain itu, jumlah waktu penayangan subtitle yang terbatas, sehingga penerjemahannyapun harus singkat, dan padat

\section{DAFTAR PUSTAKA}

Alwi, Hasan. 2003. Tata Bahasa Baku Bahasa Indonesia. Edisi ketiga. Balai Pustaka. Jakarta

Hatim,Basil dan Ian Mason. 2005. The Translator as Communicator. Routledge. London \& New York.

Haq, Ziyaul. "Penerjemahan Subtitle dari Bahasa Inggris ke dalam Bahasa Indonesia." Tesis, Universitas Negeri Jakarta: 2014.

Liang, Liji, Huang, Chenfang. 2007. Kamus Praktis Indonesia-Tionghoa TionghoaIndonesia. Cetakan keempat. Dian Rakyat. Jakarta.

Liu, Yuehua et al. 2007. 使用现代汉语语法。 商务印书馆. 北京

Moentaha, Solihen. 2008. Bahasa dan Terjemahan. Kesaint Blanc. Jakarta

Sayogie, Frans. 2014. Teori dan Praktik Penerjemahan. Cetakan Pertama. Transpustaka. Tangerang. 